OPEN ACCESS

Edited by:

Geanncarlo Lugo-Villarino, Institute of Pharmacology and Structural Biology (CNRS), France

Reviewed by: Ezio Ricca,

University of Naples Federico II, Italy Aude Remot,

Institut national de la recherche agronomique (INRA), France

*Correspondence:

Liangmeng Wei Imwei@sdau.edu.cn; Tongjie Cha chaitj117@163.com

Specialty section: This article was submitted to Microbial Immunology, a section of the journal Frontiers in Immunology

Received: 17 January 2017 Accepted: 13 March 2017 Published: 29 March 2017

Citation:

Guo M, Wu F, Hao G, Qi Q, Li R, Li N, Wei L and Chai T (2017) Bacillus subtilis Improves Immunity and Disease Resistance in Rabbits.

Front. Immunol. 8:354. doi: 10.3389/fimmu.2017.00354

\section{Bacillus subtilis Improves Immunity and Disease Resistance in Rabbits}

\author{
Mengjiao Guo ${ }^{1,2}$, Fahao $\mathrm{Wu}^{1}$, Guangen $\mathrm{Hao}^{1}$, Qin $\mathrm{Qi}^{3}$, Rong $\mathrm{Li}^{1}$, Ning $\mathrm{Li}^{1,2}$, Liangmeng Wei ${ }^{1 *}$ \\ and Tongjie Chai ${ }^{1 *}$ \\ 'College of Veterinary Medicine, Shandong Agricultural University, Sino-German Cooperative Research Centre for Zoonosis \\ of Animal Origin of Shandong Province, Tai'an City, China, ${ }^{2}$ Collaborative Innovation Center for the Origin and Control of \\ Emerging Infectious Diseases, Taishan Medical University, Tai'an City, China, ${ }^{3}$ Tai'an City Central Hospital, Tai'an City, China
}

Probiotics such as Lactobacillus and Bifidobacterium have been successfully used to promote growth and prevent diseases. Previous reports have demonstrated that Bacillus subtilis (B. subtilis) was a potential probiotic for animals. In this research, $180 \mathrm{~B}$. subtilis were isolated from the soil, identified, and investigated in vitro. Furthermore, five $B$. subtilis were selected and mixed to investigate their effect on growth performance, immune response, intestine microbiota, and disease resistance in rabbits. Rabbits with a diet of $10^{6} \mathrm{CFU} \mathrm{g} \mathrm{g}^{-1}$ mixed $B$. subtilis exhibited the best growth performance and higher serum $\lg G$ and $\lg A$ than controls $(P<0.05)$. Moreover, dairy with $B$. subtilis can promote the balance of intestinal flora. The major proinflammatory factor and $\beta$-defensin were upregulated compared with the controls. After 7 weeks of feeding, the survival rate of the rabbits fed with $B$. subtilis was significantly higher than those in the control groups postinfected with Escherichia coli. At the same time, this study detected higher expression of $\beta$-defensin and reduced bacteria contents of the heart and cecal contents from the diet mixed with $B$. subtilis compared with the control groups. In conclusion, dietary supplementation with $B$. subtilis for rabbits could improve growth performance, intestinal homeostasis, and immune organ index and enhance innate immune response as well as disease resistance. These findings showed that the induction of $\beta$-defensin by $B$. subtilis might be an interesting new therapeutic strategy to strengthen innate defense mechanisms.

Keywords: probiotics, Bacillus subtilis, growth performance, innate immunity, disease resistance

\section{INTRODUCTION}

Antibiotics used in animal breeding introduce problems while improving growth performance (1). The administration of antibiotics, whether therapeutically or prophylactically, disturbs the normal microbiotic balance of the host (2). Consequently, an awareness of antimicrobial-resistant microorganisms caused by antibiotics encourages the development of probiotics (3). Probiotics are a safe alternative to antibiotics and are supplemented in the diet to prevent diseases and promote growth. Due to the spore's resistance, survival in extreme environments, and long-term storage, sporeforming Bacillus spp. are considered to be suitable probiotics (4). They not only produce certain essential nutrients, such as amino acids, and vitamins K and B12 to promote growth performance (5) but they also promote the proliferation of beneficial anaerobic bacteria by consuming the free oxygen 
in the intestinal tract (6). In a previous study, Bacillus subtilis (B. subtilis) DJM-51 isolated from soil demonstrated strong antagonism toward the tomato pathogen Clavibacter michiganense subsp. michiganense ATCC 7429 (7).

According to guidelines for evaluating probiotics in food reported by a joint UN Food and Agricultural Organization World Health Organization working group, resistance to gastric acidity and bile salts are two of the most widely used in vitro tests based on both survival and growth studies. Furthermore, given serious concerns about increased resistance to antibiotics due to their regular use as additives, one aspect of probiotics that needs to be analyzed is antibiotic resistance. Probiotic strains, as well as bacteria used in food, can harbor resistant genes that can be transferred to pathogenic bacteria (8). As a result, probiotic strains intended for meat animals should be screened for antibiotic resistance (9).

The advantages of probiotics on hosts range from improved metabolism, immunostimulation, and anti-inflammatory status to the elimination of pathogens. Innate immunity is the first line of defense against the colonization of pathogens, and it plays a critical role in the pathogenesis and progression of intestinal disorders. The current findings confirmed that probiotics promote gut health through stimulation of the innate immune system in chronic Crohn's disease-like ileitis mouse model (10). Recently, it was reported that dietary $B$. subtilis reduced clinical signs of enteric diseases, such as Salmonella, or clostridial diseases, such as necrotic enteritis, which correlated with increased innate immunity in broiler chickens $(11,12)$.

Several bacterial diseases afflict the rabbit breeding industry, including pathogenic Escherichia coli (E. coli) infection and rabbit Clostridium perfringens disease $(13,14)$. Treatment for the diseases cannot involve the use of long-term antibiotics due to their negative effects. For example, antibiotic-associated diarrhea is caused by Clostridium or Staphylococcus aureus (15). Probiotics, including potentially beneficial bacteria, enter the guts of humans and other animals, where their beneficial qualities improve intestinal balance, modulate and stimulate immune function, produce inhibitory compounds, and compete for chemicals and adhesion sites $(16,17)$. Many studies involving both pig and poultry diets with B. subtilis led to a reduction of Clostridium and Coliforms in host guts $(18,19)$. As an alternative, probiotics have shown considerable promise in promoting the health and performance of rabbits $(20,21)$.

In response, to identify potential candidate probiotics for rabbits, this study separated B. subtilis strains from the soil, screened for the strain with the best performance in an in vitro probiotic potential evaluation, and assessed that strain's effects on weaning rabbits in a practical assessment.

\section{MATERIALS AND METHODS}

\section{B. subtilis and Pathogen}

Soil samples were collected at a depth of $10 \mathrm{~cm}$ under the earth's surface from Mount Tai, which is located in Taian city in the Shandong Province of China. First, $10 \mathrm{~g}$ of soil were suspended in $100 \mathrm{~mL}$ of sterile water in a conical flask. After incubation at $80^{\circ} \mathrm{C}$ for $1 \mathrm{~h}$, the culture was diluted and spread on modified agar plates (glucose $5 \mathrm{~g}$, yeast extract $5 \mathrm{~g}$, peptone $5 \mathrm{~g}$, beef paste $5 \mathrm{~g}$, $\mathrm{NaCl} 5 \mathrm{~g}$, and agar powder $20 \mathrm{~g}$ in $1 \mathrm{~L}$ of sterilized water with $\mathrm{pH}$ $7.0-7.2$ ) and incubated at $37^{\circ} \mathrm{C}$ for $24-72 \mathrm{~h}$. Suspected colonies were subjected to Gram stain and biochemical tests, including an arabinose biochemical tube test, glucose biochemical tube test, mannitol biochemical tube test, $3 \% \mathrm{NaCl}$ gelatin biochemical tube test, and MR-VP biochemical tube test. Following those tests, 16S rRNA sequencing was performed with universal primers 27F (5'-AGAGTTTGATCCTGGCTCAG-3') and 1492R (5'-GGTTACCTTGTTACGACTT-3'), and the sequences were blasted in NCBI.

The bacterial pathogen, enterohemorrhagic E. coli, was previously isolated from clinically infected rabbits developing acute diarrhea and stored by the Environmental Microbiology Laboratory at Shandong Agricultural University.

\section{Screening for Probiotic Properties In Vitro}

\section{Artificial Gastric Juice, Intestinal Juice, and Bile Salt Tolerance}

This study was designed as in a model gastrointestinal tract experiment to investigate the survival of $B$. subtilis. Overnight cultures of $B$. subtilis were centrifuged at $3,000 \times g$ for $10 \mathrm{~min}$, washed twice with phosphate buffer saline, and resuspended in a new liquid medium $\left(10^{8} \mathrm{CFU} \mathrm{mL}^{-1}\right)$. The new media were adjusted to $\mathrm{pH} 2.5$ by adding a hydrochloric acid solution with $1 \%$ pepsin or to $\mathrm{pH} 7.2$ with $1 \%$ trypsin and incubated at $37^{\circ} \mathrm{C}$. At 0,1 , and $2 \mathrm{~h}$ of incubation, $100 \mu \mathrm{L}$ of the cultures were removed and spread on modified nutrition agar for cell number estimation. Respectively, the bacterial suspensions were inoculated into modified nutrition broth with $0.3 \%$ bile salt and cultured at $37^{\circ} \mathrm{C}$ for $24 \mathrm{~h}$. Optical density at $600 \mathrm{~nm}$ (OD600) was measured and compared to a control culture without bile salts.

\section{Protease Assay}

These isolates were screened for neutral and alkaline protease production. Overnight cultures of $B$. subtilis strains were centrifuged at $6,000 \times g$ for $15 \mathrm{~min}$, and then the supernatant was assayed for protease activity according the SB/T 10317-1999 (22).

\section{Antimicrobial Activities}

The well diffusion method was performed on agar using cultured broth. Briefly, the target strain $\left(10^{6} \mathrm{CFU} \mathrm{mL} \mathrm{m}^{-1}\right)$ was incorporated into agar $(1 \% \mathrm{w} / \mathrm{v})$ plates, which were mixed for uniformity and poured onto plates to solidify. Overnight cultures of B. subtilis $\left(10^{8} \mathrm{CFU} \mathrm{mL}^{-1}\right)$ were transferred to holes $(5-\mathrm{mm}$ diameter) punched into the agar palates. The plates were then incubated as anaerobic or aerobic at $37^{\circ} \mathrm{C}$ for $24 \mathrm{~h}$, depending on the target strain, and the antimicrobial ability was recorded as being in the inhibition zone (23).

\section{Antibiotic Susceptibility}

Bacillus subtilis suspensions were spread on Muller-Hinton agar plates, onto which antibiotic disks of penicillin, kanamycin, doxycycline, tetracycline, gentamicin, lincomycin, erythromycin, cefotaxime, and streptomycin were placed. After $24 \mathrm{~h}$ incubation at $37^{\circ} \mathrm{C}$, the inhibition zone was measured (24). 


\section{Animals and Cells}

The healthy weaned New Zealand White rabbits (35 days) were kept in the same environment with sufficient room, feed, and ventilation. The rabbits were fed with a basal diet supplemented with $0,10^{5}, 10^{6}$, and $10^{7} \mathrm{CFU} \mathrm{g}^{-1} \mathrm{~B}$. subtilis cells (mixture of BYS2, BQ3, BD17, BG5, and BGY12). The formula of the basic diet for each group is shown in Table 1. The rabbits were handled in accordance with the appropriate biosecurity guidelines, and all experimental protocols were approved by the Shandong Agricultural University Animal Care and Use Committee (no. SDAUA-2015-005).

Rabbit kidney (RK-13) cells were grown in DMEM (GIBCO, Grand Island, USA) containing 10\% fetal bovine serum (Transgen, Beijing, China) at $37^{\circ} \mathrm{C}$ in $5 \% \mathrm{CO}_{2}$.

\section{$16 S$ rRNA Gene Sequencing and Analysis}

The cecal contents bacterial DNA of each sample was extracted using HiPure Stool DNA Kit B (Magen, Shanghai, China) following the manufacturer's instructions. The DNA extractions were quantified by ultraviolet spectroscopy and amplified using universal primers of $341 \mathrm{~F}$ (CCTACGGGNGGCWGCAG) and 806R (GGACTACHVGGGTATCTAAT) to target the V3-V4 domain of bacterial 16S rRNA. The amplicons were normalized, pooled, and sequenced on the Illumina GAIIx platform.

The raw Illumina fastq files were quality-filtered, de-multiplexed, and analyzed using quantitative insights into microbial ecology. Sequences with more than one ambiguous nucleotide or within correct barcodes or primers were removed. The Ribosomal Database Project classifier was used to classify tags into different taxonomies against Greengenes Database (version 20101006) with confidence threshold of 0.5. The software Mothur was used to cluster tags of more than $97 \%$ identity into operational taxonomic units (OTUs), and then the abundances of OTUs were calculated.

TABLE 1 | Composition and nutrient levels of the experimental diet (airdry basis).

\begin{tabular}{lrlr}
\hline Ingredients & $\begin{array}{c}\text { Content } \\
\text { (\%) }\end{array}$ & Composition & Content \\
\hline Soybean meal & 5.00 & CP (\%) & \\
Wheat bran & 16.00 & EE (\%) & 16.04 \\
Alfalfa meal & 6.00 & CF (\%) & 3.34 \\
Sunflower meal & 9.00 & Digestible energy (MJ/kg) & 16.73 \\
Corn germ meal & 24.00 & Ca (\%) & 0.32 \\
Corn & 10.00 & P (\%) & 0.42 \\
Rice husk & 6.00 & Lys (\%) & 0.49 \\
Soybean phospholipids & 3.00 & Met (\%) & 0.18 \\
Barley husk & 10.00 & & \\
Haulm powder & 9.00 & & \\
Limestone & 1.00 & & \\
Premix & 1.00 & & \\
Total & 100 & & \\
\hline
\end{tabular}

aPremix provided the following per kilogram of diets: VA, 8,000 IU; VD, 31,000 IU; VE, 50 mg; Lys, 1.5 g; Met, $1.5 \mathrm{~g}$; Cu, 50 mg; Fe, 100 mg; Mn, 30 mg; Mg, 150 mg; l,

$0.1 \mathrm{mg}$; Se, $0.1 \mathrm{mg}$.

${ }^{b}$ Calculated values.

\section{Quantitative Real-time RT-PCR}

Total RNA was extracted from the spleen and jejunum of rabbits using TransZol Up (Transgen, Beijing, China), and $1 \mu \mathrm{g}$ total RNA was reverse-transcribed with HiScript ${ }^{\circledR}$ II Q Select RT SuperMix for qPCR (+gDNA wiper) (Vazyme, Nanjing, China). Quantitative real-time PCR (qRT-PCR) oligonucleotide primers for immune-related genes and glyceraldehyde-3-phosphate dehydrogenase (GAPDH) were designed using Primer 3 software (http://bioinfo.ut.ee/primer3-0.4.0/), based on the published GenBank sequence (Table 2). qRT-PCR was performed using

TABLE 2 | Primers used in this study.

\begin{tabular}{|c|c|c|c|}
\hline Primer name & Sequence $\left(5^{\prime}-3^{\prime}\right)$ & $\begin{array}{l}\text { Product } \\
\text { size (bp) }\end{array}$ & GenBank no. \\
\hline NOD1 $F$ & acaaggttcgcaaaatcctg & 169 & XM008261590.2 \\
\hline NOD1 $R$ & ttgacaatggctttgctctg & & \\
\hline NOD2 F & caacctcaagggcttctcag & 241 & XM008275042.2 \\
\hline NOD2 R & caggaaatgctgcaagatca & & \\
\hline NLRC3 F & acatcatccgaggcaatctc & 168 & XM017338739.1 \\
\hline NLRC3 R & tctggtcctcagggaacatc & & \\
\hline NLRX1 F & gtttcgggaggaggactacc & 204 & XM017338655.1 \\
\hline NLRX1 R & tccatgttcttgatgggaca & & \\
\hline$\| L-1 \beta F$ & tggcacgtatgagctgaaag & 115 & NM001082201.1 \\
\hline IL-1 $1 \beta R$ & ggccacaggtatcttgtcgt & & \\
\hline IL-4 F & cactccggcagttctacctc & 104 & NM001163177.1 \\
\hline IL-4 R & gcagaggttcctgtcgagtc & & \\
\hline IL-8 F & ctctcttggcaaccttcctg & 165 & KT216053.1 \\
\hline IL-8 R & ttgcacagtgaggtccactc & & \\
\hline IL-10 F & aaaagctaaaagccccagga & 143 & NM001082045.1 \\
\hline IL-10 R & cgggagctgaggtatcagag & & \\
\hline $\mathrm{IFN}-\gamma \mathrm{F}$ & ctcgaatttcggtggatgat & 118 & DQ680162.1 \\
\hline $\mathrm{IFN}-\gamma \mathrm{R}$ & agcgtctgactcctttttcg & & \\
\hline PKR F & attggccattcatcatggtt & 162 & XM008258792.2 \\
\hline PKR R & ttctcggcagcatttctctt & & \\
\hline OAS F & gagctcctgaccatctacgc & 182 & XM002722126.3 \\
\hline OAS R & gccttgagctgtttcctgac & & \\
\hline DEFB114 F & taccagccacatgctctttg & 134 & XM017344866.1 \\
\hline DEFB114 R & cctgtcgacacagcaaatct & & \\
\hline DEFB124 F & gcaccaagcaagagtccttc & 117 & XM017342171.1 \\
\hline DEFB124 R & acgccagagccagctactta & & \\
\hline DEFB125 F & cgtgctgcatctccttaaca & 114 & XM008256168.2 \\
\hline DEFB125 R & gcgaagcagaaaattgatcc & & \\
\hline DEFB127 F & cccacagtaaccgagcaact & 126 & XM002710854.1 \\
\hline DEFB127 R & gctgaggcagcagtatctcc & & \\
\hline DEFB128 F & gggctcaaggctttctcttt & 200 & XM017342173.1 \\
\hline DEFB128 R & aaatctcgcctagcttgcac & & \\
\hline DEFB134 F & agcctgtctgcctggagtag & 156 & XM017337690.1 \\
\hline DEFB134 R & gatgaggagaggcttcatgg & & \\
\hline DEFB135 F & gctgcatctccaaatccaat & 116 & XM017337693.1 \\
\hline DEFB155 R & tagtgggatggtgcaactga & & \\
\hline NP 5 F & aggcaggcgtgttctgtact & 154 & M64602.1 \\
\hline NP 5 R & ggtctccacgcaaataagga & & \\
\hline $\begin{array}{l}\text { Glyceraldehyde- } \\
\text { 3-phosphate } \\
\text { dehydrogenase } \\
\text { (GAPDH) F }\end{array}$ & aggtcatccacgaccacttc & 202 & NM001082253.1 \\
\hline GAPDH R & gtgagtttcccgttcagctc & & \\
\hline
\end{tabular}


TransStart Tip Green qPCR SuperMix (Transgen Biotech Co., Ltd., Beijing, China) and the Applied Biosystems 7500 Fast Real-Time PCR System (Applied Biosystems, CA, USA). The qRT-PCR conducted in a total volume of $20 \mu \mathrm{L}$ and the amplification steps consisted of $94^{\circ} \mathrm{C}$ for $30 \mathrm{~s}, 40$ cycles of denaturation at $94^{\circ} \mathrm{C}$ for $5 \mathrm{~s}$, and extension $60^{\circ} \mathrm{C}$ for $34 \mathrm{~s}$, and a dissociation curve analysis. The purified PCR products were cloned into the pMD18-T and sequenced to verify correct amplification. Each sample was performed in triplicate. Data were calculated based on the $2^{-\Delta \Delta \mathrm{Ct}}$ method. The relative expression mRNA was normalized to GAPDH.

TABLE 3 | Survival rate of Bacillus subtilis at artificial gastric juice, intestinal juice, and bile (\%).

\begin{tabular}{lccccc}
\hline Strains & \multicolumn{2}{c}{$\mathbf{1 ~ h}$} & \multicolumn{2}{c}{$\mathbf{2 ~ h}$} & Bile \\
\cline { 2 - 5 } & $\begin{array}{c}\text { Gastric } \\
\text { juice }\end{array}$ & $\begin{array}{c}\text { Intestinal } \\
\text { juice }\end{array}$ & $\begin{array}{c}\text { Gastric } \\
\text { juice }\end{array}$ & $\begin{array}{c}\text { Intestinal } \\
\text { juice }\end{array}$ & \\
\hline BYS2 & 100 & 100 & 100 & 100 & $47 \pm 2.8$ \\
BQ3 & 100 & 100 & 100 & 100 & $49 \pm 3.3$ \\
BGY12 & 100 & 100 & 100 & 100 & 100 \\
BD17 & $81 \pm 9.2$ & 100 & $73 \pm 4.3$ & 100 & $48 \pm 4.7$ \\
BG5 & $78 \pm 4.3$ & 100 & $82 \pm 5.2$ & 100 & $65 \pm 4.0$ \\
B. subtilis & $41 \pm 3.1$ & 100 & $17 \pm 0.7$ & 100 & $38 \pm 1.8$ \\
CMCC63501 & & & & & \\
\hline
\end{tabular}

Values were expressed as means $\pm S D$ s of three independent repetitions.

\section{Statistical Analysis}

Statistical analyses were performed with SPSS 19.0, and one-way analysis of variance was used to identify differences among the groups. When variances were not homogeneous, the data were analyzed by the non-parametric Mann-Whitney $U$ test or the Kruskal-Wallis test. The survival rate of rabbits was analyzed using the Kaplan-Meier method. Statistically significant differences required that $P<0.05$.

\section{RESULTS}

\section{Probiotic Potential Evaluation of B. subtilis In Vitro}

According to colony morphology and the results of microscopic examination, Gram-positive Bacillus strains with the typical volcano shape were selected as subjects for biochemical experiments. In total, $180 \mathrm{~B}$. subtilis were isolated from the soil and confirmed by $16 \mathrm{~S}$ rRNA sequencing. Five strains (BYS2, BQ3, BD17, BG5, and BGY12) exhibited excellent probiotic properties in vitro, including artificial gastric juice, intestinal juice, and bile salt tolerance (Table 3). BG5 and BGY12 had good performance in protease activities (Table 4). BYS2, BQ3, and BD17 showed good antimicrobial activities (Figure 1). All five B. subtilis were susceptible to the common antibiotics tested (data not shown). The 16S rRNA sequence of five B. subtilis was deposited in GenBank (Genbank no. KY750231-235).

TABLE 4 | Neutral and alkaline protease production of Bacillus subtilis.

\begin{tabular}{lcccrr}
\hline & BYS2 & BQ3 & BD17 & BGY12 & B. subtilis CMCC63501 \\
\hline Neutral protease $\left(\mathrm{U} \mathrm{mL}^{-1}\right)$ & $1.3 \pm 0.6$ & 0 & 0 & $50.2 \pm 3.8$ & $60.7 \pm 5.7$ \\
Alkaline protease $\left(\mathrm{U} \mathrm{mL}^{-1}\right)$ & $4.3 \pm 1.6$ & $2.3 \pm 1.5$ & $3.4 \pm 0.9$ & $48.6 \pm 3.2$ & $42.3 \pm 5.1$ \\
\hline
\end{tabular}

Values were expressed as means \pm SDs of three independent repetitions.

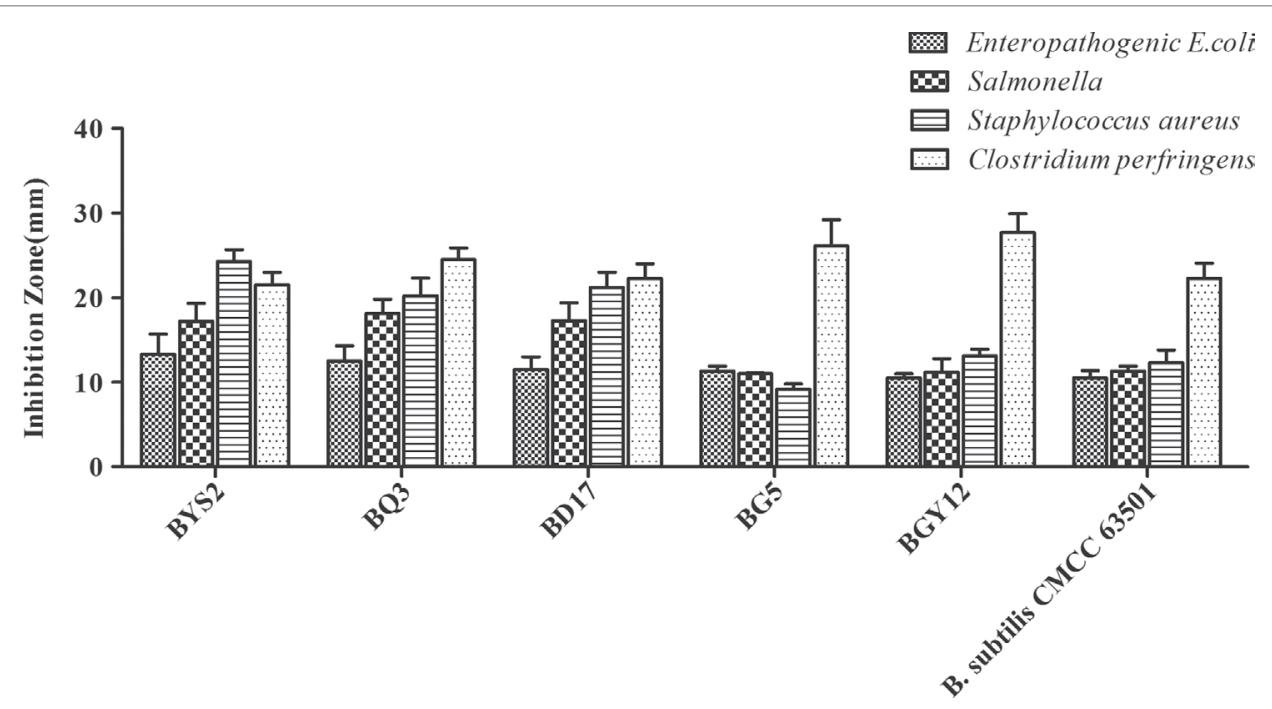

FIGURE 1 | Antibacterial activity of Bacillus subtilis against four pathogenic bacteria (Enteropathogenic Escherichia coli CVCC 1512, Salmonella CMCC 50094, Staphylococcus aureus ATCC 25923, and Clostridium perfringens NCTC 528). Bars represented the means \pm SDs of three independent repetitions. 


\section{Growth Performance and Serum Immunoglobulin}

After 4, 5, 6, and 7 weeks of feeding, rabbits fed with the diet of $10^{6} \mathrm{CFU} \mathrm{g}^{-1}$ B. subtilis showed the best growth performance and were heavier $(P<0.05)$ than the control diet rabbits. Rabbits fed a diet with $10^{7} \mathrm{CFU} \mathrm{g} \mathrm{g}^{-1} B$. subtilis showed higher growth performance than the controls, but the difference was not significant $(P>0.05)$. However, no significant differences were observed between rabbits fed with $10^{5} \mathrm{CFU} \mathrm{g} \mathrm{g}^{-1} \mathrm{~B}$. subtilis diets and the controls after 4,5, 6, and 7 weeks of feeding (Figure 2A). After 4, 5, 6, and 7 weeks of feeding, rabbits fed with the diet of $10^{6} \mathrm{CFU} \mathrm{g^{-1 }}$ B. subtilis had higher $(P<0.05)$ serum IgG and IgA than the controls. However, the serum IgA of rabbits fed with $10^{7} \mathrm{CFU} \mathrm{g^{-1 }} B$. subtilis were significantly different $(P<0.05)$ than the controls after only 5 and 6 weeks of feeding (Figures 2B,C). Consistent with the growth performance results, the serum immunoglobulin of rabbits fed $10^{5} \mathrm{CFU} \mathrm{\textrm {g } ^ { - 1 }}$ B. subtilis were virtually unchanged, especially IgM (Figure 2D). Based on these results research above, rabbits fed with the diet of $10^{6} \mathrm{CFU} \mathrm{g}^{-1}$ B. subtilis were chosen for the following assays.

\section{Immune Organ Index}

As shown in Figure 3, the relative weights of the thymus and spleen were significantly increased by diet with $B$. subtilis after 5 weeks of feeding. However, there was no difference between the group supplemented with $B$. subtilis and the controls after 7 weeks of feeding.

\section{Taxonomic Composition of Intestine Microbiota}

High-throughput sequence analysis of bacterial 16S rRNA V3$\mathrm{V} 4$ region was conducted on cecal contents of rabbits after 5 and 7 weeks of feeding. As shown in Figure 4A, the 95.0-96.5\%

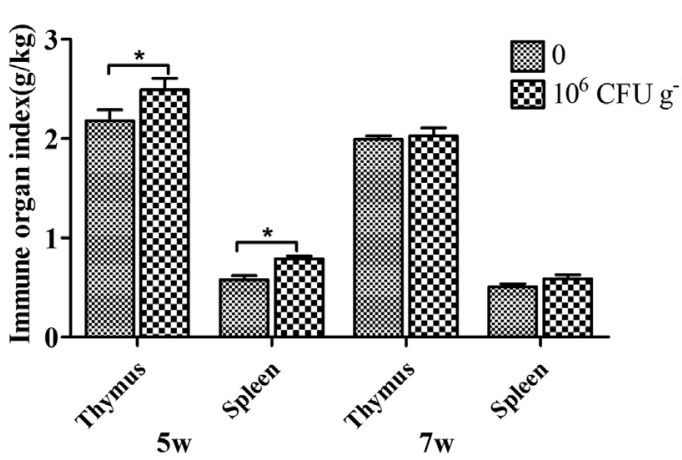

FIGURE 3 | Effects of dietary supplementation with Bacillus. subtilis on immune organ index in rabbits. The thymus and spleen were weighed to calculate the immune organ index. Bars represented the means \pm SDs of three independent experiments (five rabbits per experiment). Mann-Whitney $U$ test was conducted to examine differences. ${ }^{\star} P<0.05$.
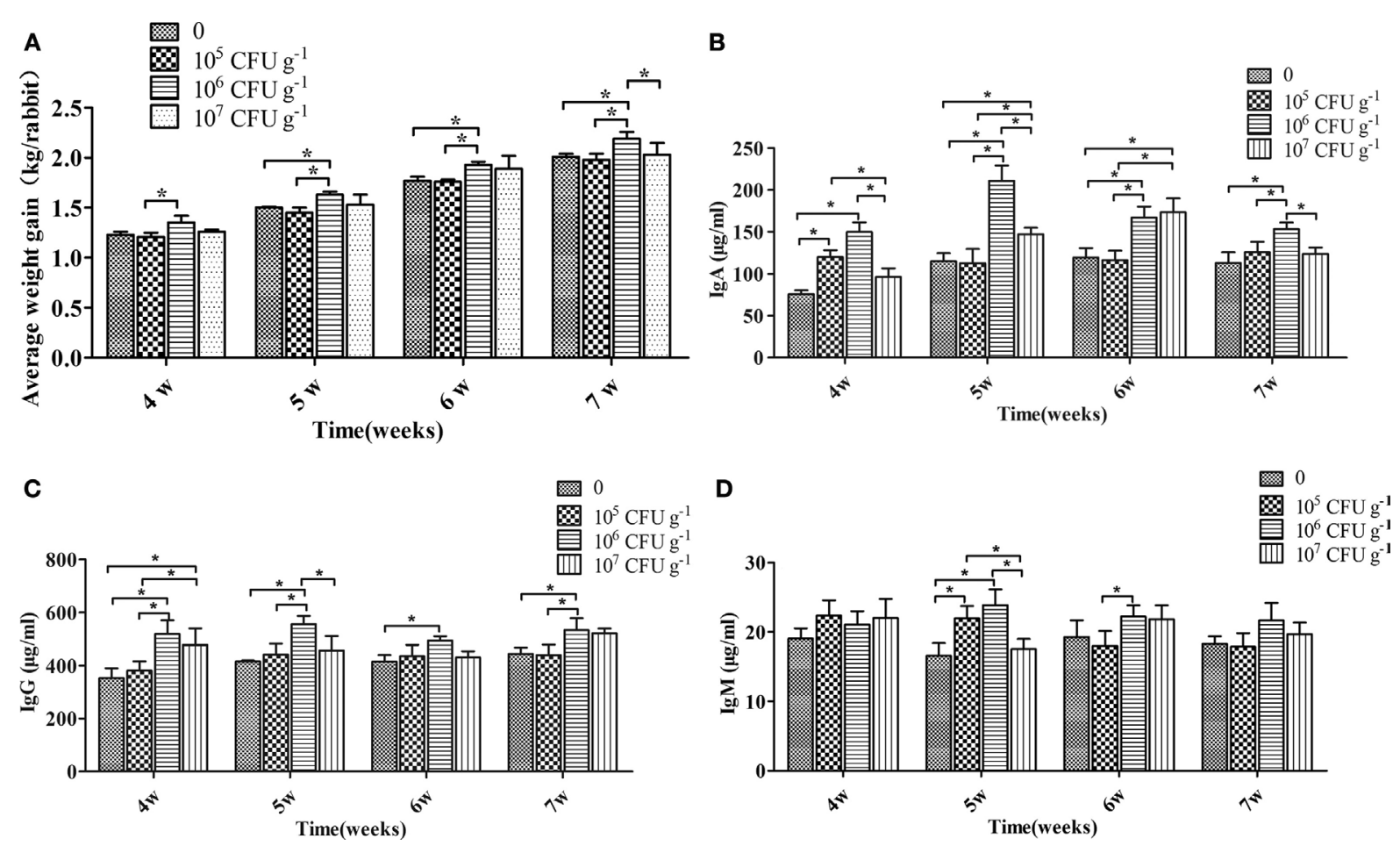

FIGURE 2 | Effects of dietary supplementation with Bacillus subtilis on growth performance and serum immunoglobulin in rabbits. (A) The rabbits' individual body weights were measured during feeding weeks $4-7$. Bars were expressed as means \pm SDs of three independent experiments (20 rabbits per experiment). One-way analysis of variance was conducted to examine differences. ${ }^{*} P<0.05$. The blood samples were collected during feeding weeks $4-7$. The concentrations of $\lg A(\mathbf{B}), \lg G(\mathbf{C})$, and $\lg M(\mathbf{D})$ are represented. Bars represented the means \pm SDs of three independent experiments (five rabbits per experiment). Kruskal-Wallis test was conducted to examine differences. ${ }^{*} P<0.05$. 


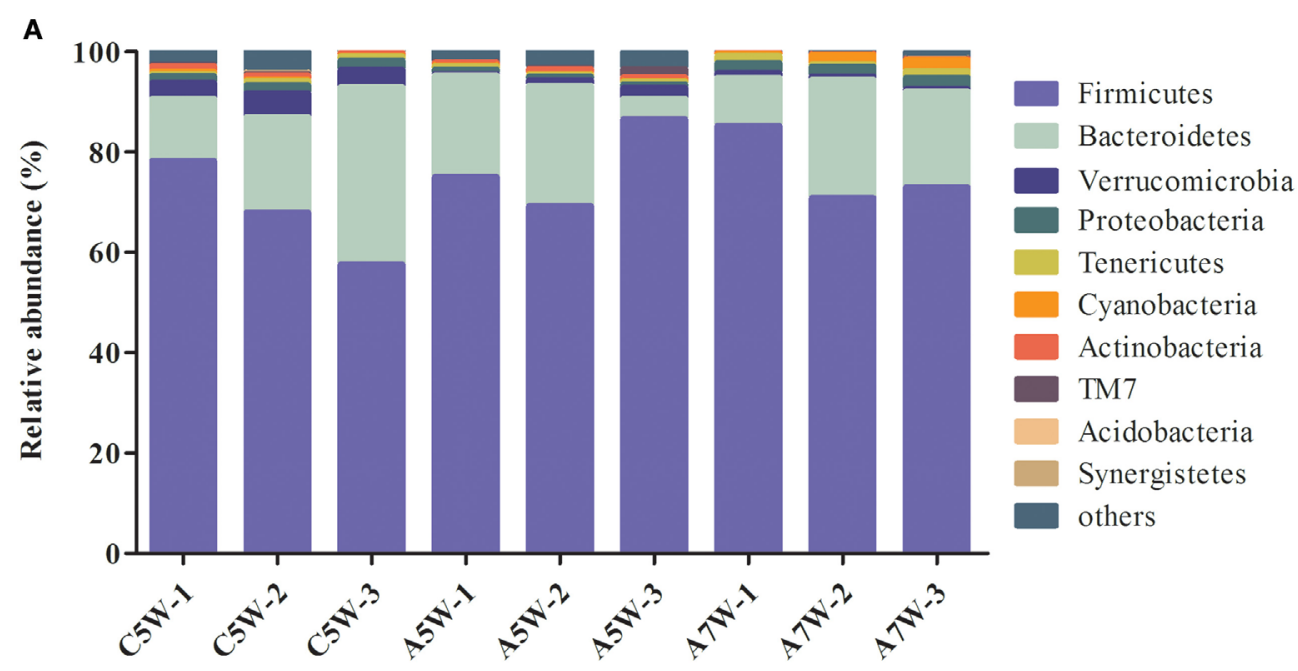

B

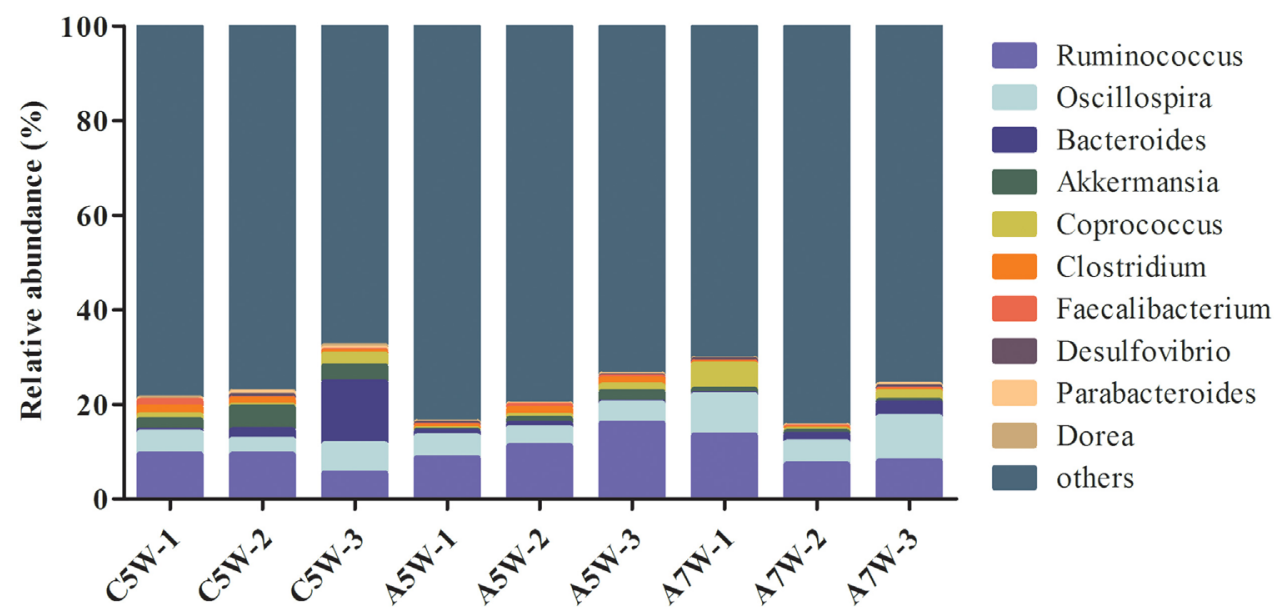

C

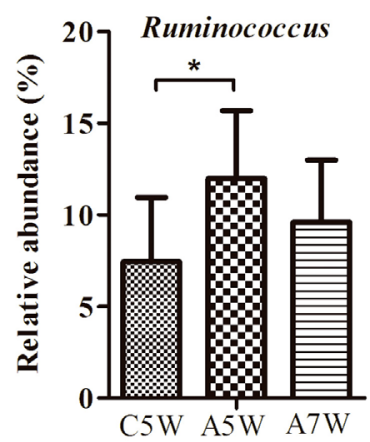

D

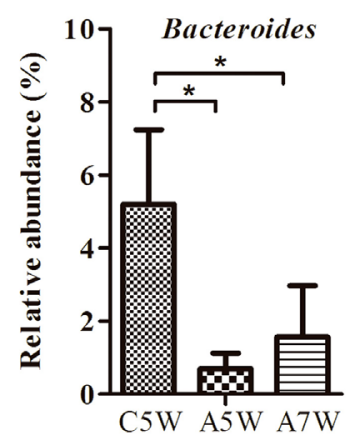

E

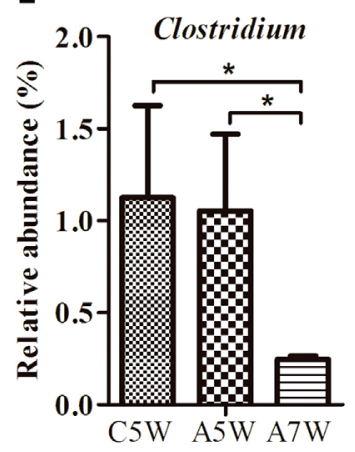

FIGURE 4 | Comparison of identified bacteria relative abundance in cecal contents. The cecal contents of rabbits fed with $10^{6} \mathrm{CFU} \mathrm{g}^{-1} \mathrm{Bacillus}$ subtilis diets and the controls were collected for high-throughput sequence analysis after 5 and 7 weeks of feeding. (A) Relative abundance at the phylum level. (B) Relative abundance at the genus level. (C) Relative abundance of three genera Ruminococcus, (D) Bacteroides, and (E) Clostridium. Bars were expressed as means \pm SDs $(n=3)$. C5W, A5W, and A7W represented sample of control, active at 5 weeks, and active at 7 weeks of feeding, respectively. Kruskal-Wallis test was conducted to examine differences. ${ }^{*} P<0.05$. 
reads belong to Firmicutes, Bacteroidetes, Verrucomicrobia, and Proteobacteria at the phylum level. The relative abundance of the phyla Firmicutes was increased after feeding B. subtilis. The shifts in bacterial composition at the phylum level were caused by the changes at the genus level (Figure 4B). In particular, the relative abundance of Ruminococcus (Figure 4C; $P<0.05)$ was increased after 5 weeks of feeding. The percentage of Bacteroides (Figure 4D; $P<0.05$ ) and Clostridium (Figure 4E; $P<0.05$ ) were significantly decreased after 5 and 7 weeks of feeding.

\section{Expression of Innate Immune-Related Genes In Vivo and In Vitro}

To determine the induction of innate immunity in rabbits fed with a diet of B. subtilis, the expressions of innate immune-related genes were examined in the spleen and jejunum of rabbits fed with the probiotic compared to the controls after 5 and 7 weeks of feeding. Figure 5A shows that expressions of nucleotide oligomerization domain (NOD) 1 were upregulated in the spleen and jejunum. After 5 weeks of feeding, it was upregulated by 2.48 fold in the spleen $(P<0.05)$. The expression of NOD-like receptor (NLR) C3 and NLRX1 was generally higher in the jejunum than in the spleen (Figures 5C,D). For example, the expression of NLRC3 was elevated by 3.74-fold in the jejunum after 7 weeks of feeding ( $P<0.05$; Figure 5C), which is 2 times higher than that in the spleen. However, the NOD 2 expression was not obviously changed (Figure 5B). The expression of proinflammatory cytokines (IL-1 $\beta$ and IL-8) was upregulated in the spleen and jejunum (Figures 5F,H), while anti-inflammatory cytokines (IL-4 and IL-10) showed slight variation (Figures 5G,I). In particular, the expression of IL-8 was upregulated by 10.46- and 5.73-fold in the spleen after 5 and 7 weeks of feeding $(P<0.05$; Figure $5 \mathrm{H})$. Figure $5 \mathrm{E}$ shows that the expression of IFN- $\gamma$ was upregulated by 2.46 -fold $(P<0.05)$ in the jejunum after 7 weeks of feeding. The antiviral proteins OAS showed no significant difference $(P>0.05$; Figure 5J), whereas the expression of PKR in jejunum was upregulated by 7.45 -fold after 5 weeks of feeding $(P<0.05$; Figure $5 \mathbf{K})$. When the expressions of $\beta$-defensin (DEFB 114, DEFB 124, DEFB 125, DEFB 127, DEFB 128, DEFB 134 , and DEFB 135) and $\alpha$-defensin (NP 5) were investigated, all of these genes showed elevated expression in the spleen and jejunum after 7 weeks of feeding. The expressions of DEFB 114 and DEFB 134 were upregulated by two fold to three fold in the spleen and jejunum $(P<0.05$; Figures $5 \mathrm{~L}, \mathbf{Q})$. Moreover, the expressions of DEFB 124, DEFB 127, and DEFB 134 were upregulated in the spleen and jejunum after 5 weeks of feeding $(P<0.05$; Figures $\mathbf{5 M}, \mathbf{O}, \mathbf{Q})$. However, the expression of DEFB 125, DEFB 128, DEFB 135, and NP 5 showed no significant difference $(P>0.05$; Figures 5N,P,R,S).

To further explore the induction of innate immunity by $B$. subtilis, the RK-13 cell were stimulated by live B. subtilis and killed cells. The expressions of IL- $1 \beta$ and IL- 8 were upregulated by 18.6- and 17.2-fold, respectively, after stimulation with live B. subtilis $(P<0.05$; Figure 6), which were significantly higher than stimulation with killed cells. Similarly, the expression of DEFB127, DEFB 128, and DEFB 134 upregulated by 2.5-, 2.6-, and 2.3-fold, respectively, after stimulation with live B. subtilis
$(P<0.05)$, which were not obviously changed after stimulation with killed cells.

\section{Survival Rate}

The survival rate of rabbits fed $B$. subtilis was significantly higher than the controls after the E. coli challenge. At 1, 2, and 3 days postinfection (dpi), the survival rate of rabbits fed B. subtilis was $79.2,57.8$, and $50.6 \%$, respectively, which were higher than the control group $(P<0.05$; Figure 7A).

\section{E. coli Content in E. coli-Infected Rabbits}

As shown in Figure 7B, the number of E. coli in the heart and cecal contents in the B. subtilis group were declined compared to controls at $1 \mathrm{dpi}$. At $3 \mathrm{dpi}$, the number of $E$. coli in all tested tissues declined compared to those of $1 \mathrm{dpi}$. In particular, rabbits fed with the diet of $B$. subtilis had lower $(P<0.05)$ E. coli content in their cecal contents compared to the controls at $3 \mathrm{dpi}$.

\section{Expression of Innate Immune-Related Genes in the Spleen and Jejunum of the Infected Rabbits}

As shown in Figure 8, the expression of all innate immune-related genes was not as obvious as in the spleen and jejunum at $1 \mathrm{dpi}$. However, the expression of NOD2, NLRC3, and NLRX1 in the jejunum was significantly upregulated at $3 \mathrm{dpi}$. The expression of NLRC3, in particular, was upregulated by 18.18 -fold $(P<0.05$; Figure $8 C$ ), whereas the expression of NOD1 increased by 4.63 fold in the spleen $(P<0.05$; Figure 8A). Similarly, the expression of IL-1 $\beta$, IL-4, IL- 8 , and IFN- $\gamma$ in the spleen and jejunum showed upregulating tendencies, but to a greater extent. At $3 \mathrm{dpi}$, the expression of IFN- $\gamma$ increased 251.41-fold $(P<0.05$; Figure 8E). Furthermore, the expression level of $\beta$-defensin was generally higher in the spleen than in the jejunum at 3 dpi. DEFB 124,DEFB 125,DEFB 127, and DEFB 128 showed a relatively low expression compared with DEF114 and DEFB134, with a fold change between twofold and eightfold in the spleen or the jejunum. At 3 dpi, the expressions of DEFB 114 and DEFB 134 were upregulated and reached 78.93- and 25.89-fold ( $P<0.05$; Figures 8J,O). However, in the jejunum, the expression of DEFB 135 was upregulated by 65.69-fold at 3 dpi $(P<0.05$; Figure 8P).

\section{DISCUSSION}

To influence the gastrointestinal tract, probiotics should also be excellent in adapting to acidic conditions in the stomach and in bile salt in the duodenum. Hydrochloric acid in gastric juice can kill bacteria in food to ensure the safety of the stomach and intestines and activate pepsin for digestion. It has also been reported that good bile tolerance benefits colonization in the host's gastrointestinal tract (25). Maintaining a high survival rate in acid and bile salt tolerance tests means that an effective number of live bacteria will enter the intestinal tracts and successfully play a role. After overnight incubation, the Bacillus cultures were examined microscopically, and no more than $5 \%$ of free spores were observed. Therefore, the remarkable resistance of five $B$. subtilis strains to gastric intestinal juice and bile 

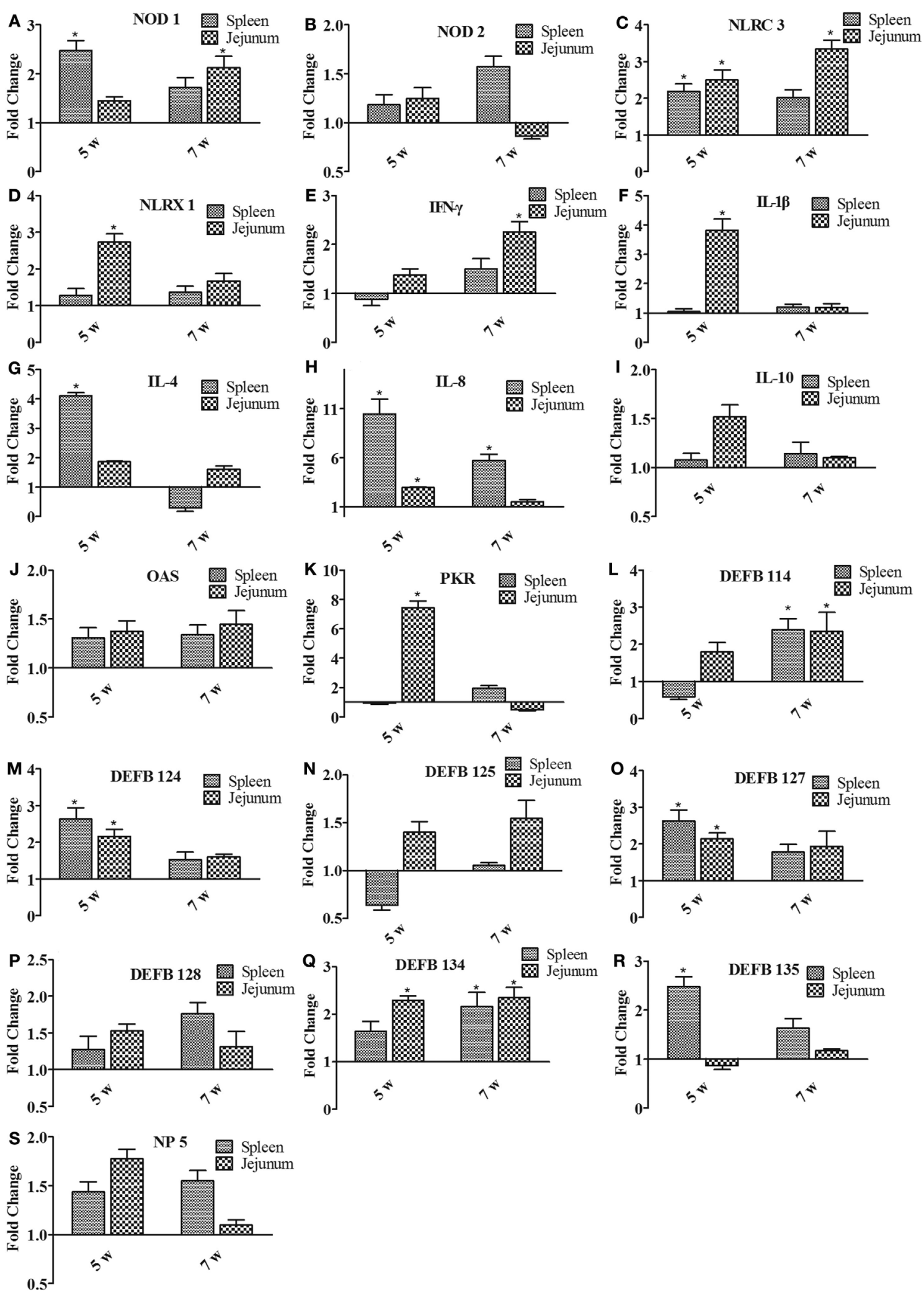

FIGURE 5 | The expression of immune-related genes in the spleen and jejunum of rabbits after $\mathbf{5}$ and $\mathbf{7}$ weeks of feeding. (A) NOD1, (B) NOD2, (C) NLRC3, (D) NLRX1, (E) IFN- $\gamma$, (F) IL-1ß, (G) IL-4, (H) IL-8, (I) IL-10, (J) OAS, (K) PKR, (L) DEFB114, (M) DEFB124, (N) DEFB125, (O) DEFB127, (P) DEFB128, (Q) DEFB134, (R) DEFB135, and (S) NP5. The fold change represents gene expression in diet with Bacillus subtilis compared to that of the controls. Bars represented the means \pm SDs of three independent experiments (five rabbits per experiment). Mann-Whitney $U$ test was conducted to examine differences. ${ }^{\star} P<0.05$. 
salt conditions can not be due to the presence of spores. Bacillus sp. can produce certain essential nutrients and extracellular enzymes, as well as provide necessary growth factors to promote host growth (5). BG5 and BGY12 had good performance in the protease activities. BYS2, BQ3, and BD17 appeared to inhibit pathogenic bacteria, and, of course, all five strains showed no antibiotic resistance. On the other hand, strain that does not have any probiotic activity or killed cells can not produce digestive enzymes, vitamins, and antibacterial substances, which were produced by probiotic. Based on these reasons, we speculated that strains without probiotic activity and killed cells have no significant effects on growth performance, intestinal flora and disease resistance.

In poultry and pigs, $B$. subtilis $\left(1.8 \times 10^{6} \mathrm{CFU} \mathrm{\textrm {g } ^ { - 1 }}\right.$ diet $)$ promoted animal growth and immune regulation $(18,26)$ and can

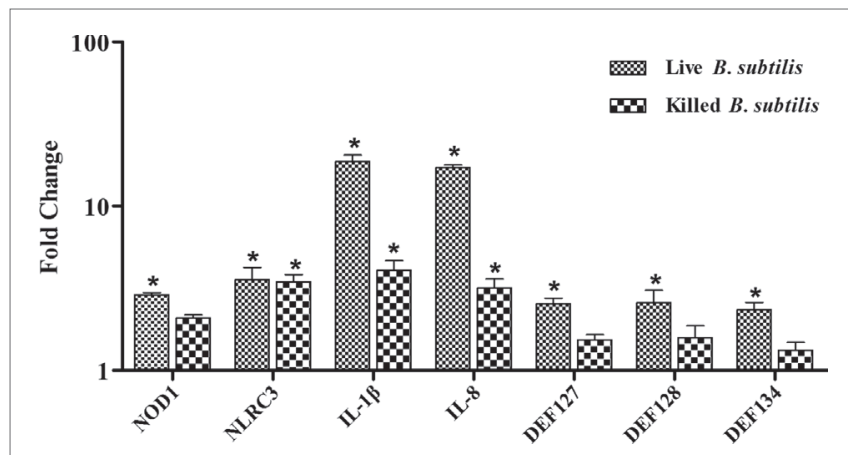

FIGURE 6 | Rabbit kidney (RK-13) cells were cocultured with live Bacillus subtilis or killed cells in DMEM without antibiotic for $\mathbf{2} \mathbf{h}$ at $37^{\circ} \mathbf{C}$. The medium was removed, and cells were washed three times with PBS containing 1\% penicillin-streptomycin solution to kill B. subtilis. RK-13 cells were cultured in DMEM containing 1\% penicillin-streptomycin solution for $24 \mathrm{~h}$. Also, $100 \mu \mathrm{l}$ of the DMEM were plated onto nutrient agar to ensure effective killing of $B$. subtilis. The fold change represents gene expression of RK-13 cells stimulated with live $B$. subtilis and killed cells compared to that of controls. Bars represented the means \pm SDs of three independent experiments. Mann-Whitney $U$ test was conducted to examine differences. ${ }^{\star} P<0.05$. also help animals resist intestinal pathogenic bacteria infection (27). In a similar study, Bacillus circulans $\left(2 \times 10^{6} \mathrm{CFU} \mathrm{g}^{-1}\right.$ diet $)$ significantly enhanced the growth performance and non-specific immunity levels and disease resistance of fish (28). In the present study, rabbits fed with a diet containing B. subtilis at $10^{6} \mathrm{CFU} \mathrm{g}^{-1}$ had significantly improved average weight gain, which might result from the production of nutrients and digestive enzymes. Rabbits fed a diet of $10^{7} \mathrm{CFU} \mathrm{g^{-1 }}$ B. subtilis did not grow as well as those fed with $10^{6} \mathrm{CFU} \mathrm{g}^{-1}$, perhaps because nutrients in the gut of rabbits was absorbed by the addition of B. subtilis. In previous research, there was no difference between the group supplemented with B. subtilis alone and the controls (29). Such discrepancies could stem from differences among experimental conditions or among species of probiotics.

In this study, dairy with $B$. subtilis significantly improved concentrations of the serum immunoglobulins IgG and IgA of rabbits. Moreover, the relative weights of the spleen were significantly increased by dietary supplementation with $B$. subtilis after 5 weeks of feeding. It can thus be deduced that B. subtilis might improve immune function, which has been reported to reduce weaning stress and improve the growth performance of rabbits at weaning (30). It has been reported that Bacillus cereus increased the concentrations of beneficial bacteria and decreased the concentration of harmful bacteria (31). In the current study, the relative abundance of Bacteroides and Clostridium were significantly decreased, and Ruminococcus increased after feeding B. subtilis. The Ruminococcus contributed to the digestion and absorption of fiber in herbivores (32). The increase of Ruminococcus may promote the growth performance of rabbits. In addition, the increase of Bacteroides and Clostridium in the intestine leads to colitis and carcinogenesis (33). These findings indicate that dairy with $B$. subtilis can regulate intestinal flora and maintain intestinal health.

The innate immune system is used as the first line of defense to various pathogens. NLRs are a kind of pattern recognition receptor (PRR). PRRs have been implicated in pathogen control and elimination and have been recently identified as key mediators of inflammatory and immune responses. There are few reports
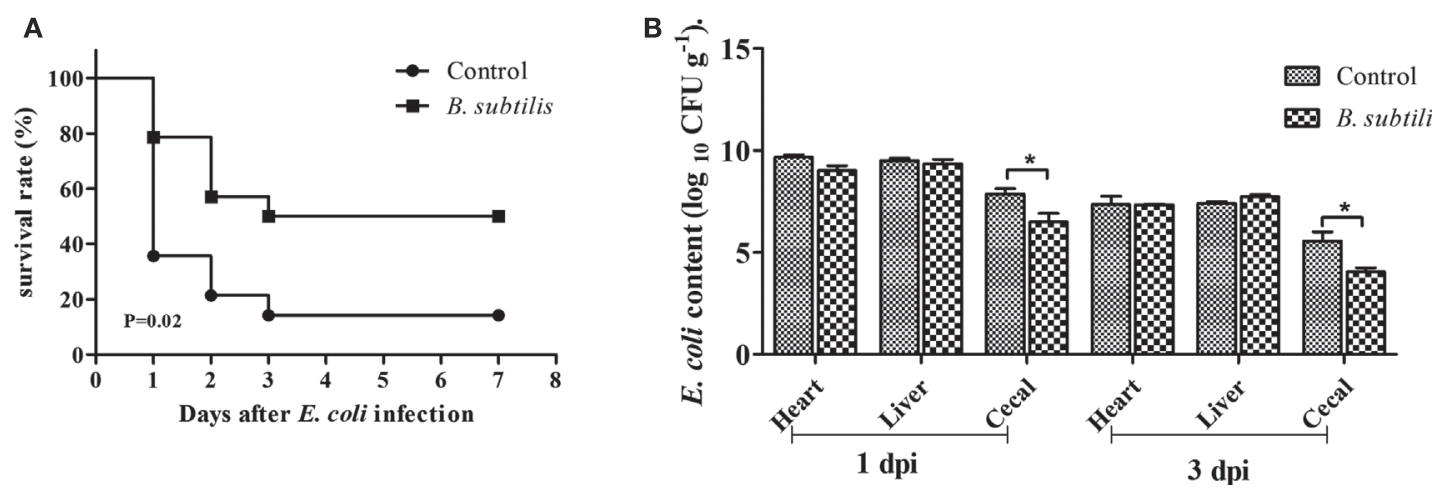

FIGURE 7 | Rabbits fed with the diet of 0 and $10^{6}$ CFU g-1 Bacillus subtilis were inoculated intraperitoneally with 1.5 mL of enterohemorrhagic Escherichia coli bacterial suspension $\left(\mathbf{1 0 ^ { 8 }} \mathbf{C F U ~} \mathbf{~ L L}-\mathbf{1}\right)$ after $\mathbf{7}$ weeks of feeding. (A) The survival rate of rabbits after infection with $E$. coli: control and rabbits fed with the diet of $10^{6} \mathrm{CFU} \mathrm{g}{ }^{-1} B$. subtilis $(n=14)$. (B) E. coli content of infected rabbits at 1 and 3 dpi $\left(\log _{10}\right.$ CFU g $\left.\mathrm{g}^{-1}\right)$. Bars represented the means \pm SDs of three independent experiments (five rabbits per experiment). Mann-Whitney $U$ test was conducted to examine differences. ${ }^{*} P<0.05$. 

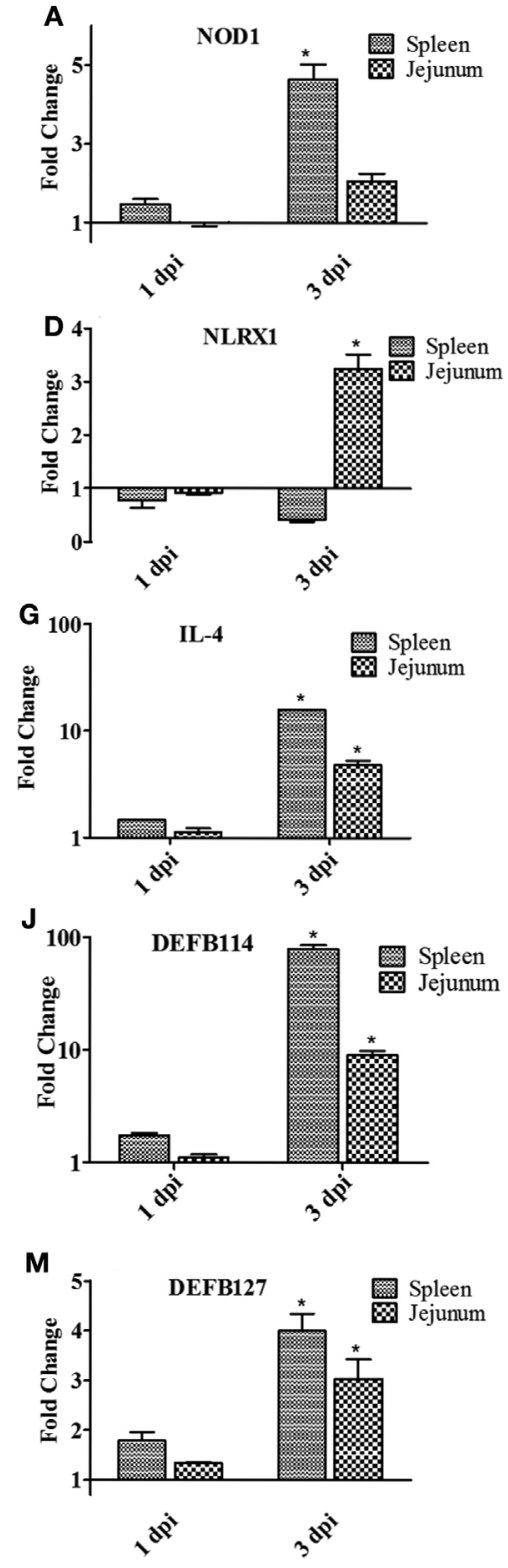

$\mathbf{P}$

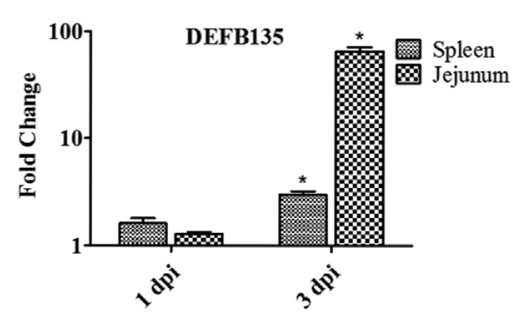

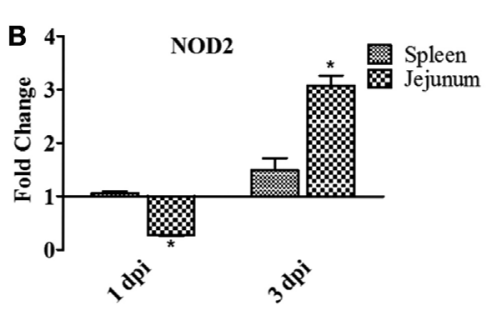
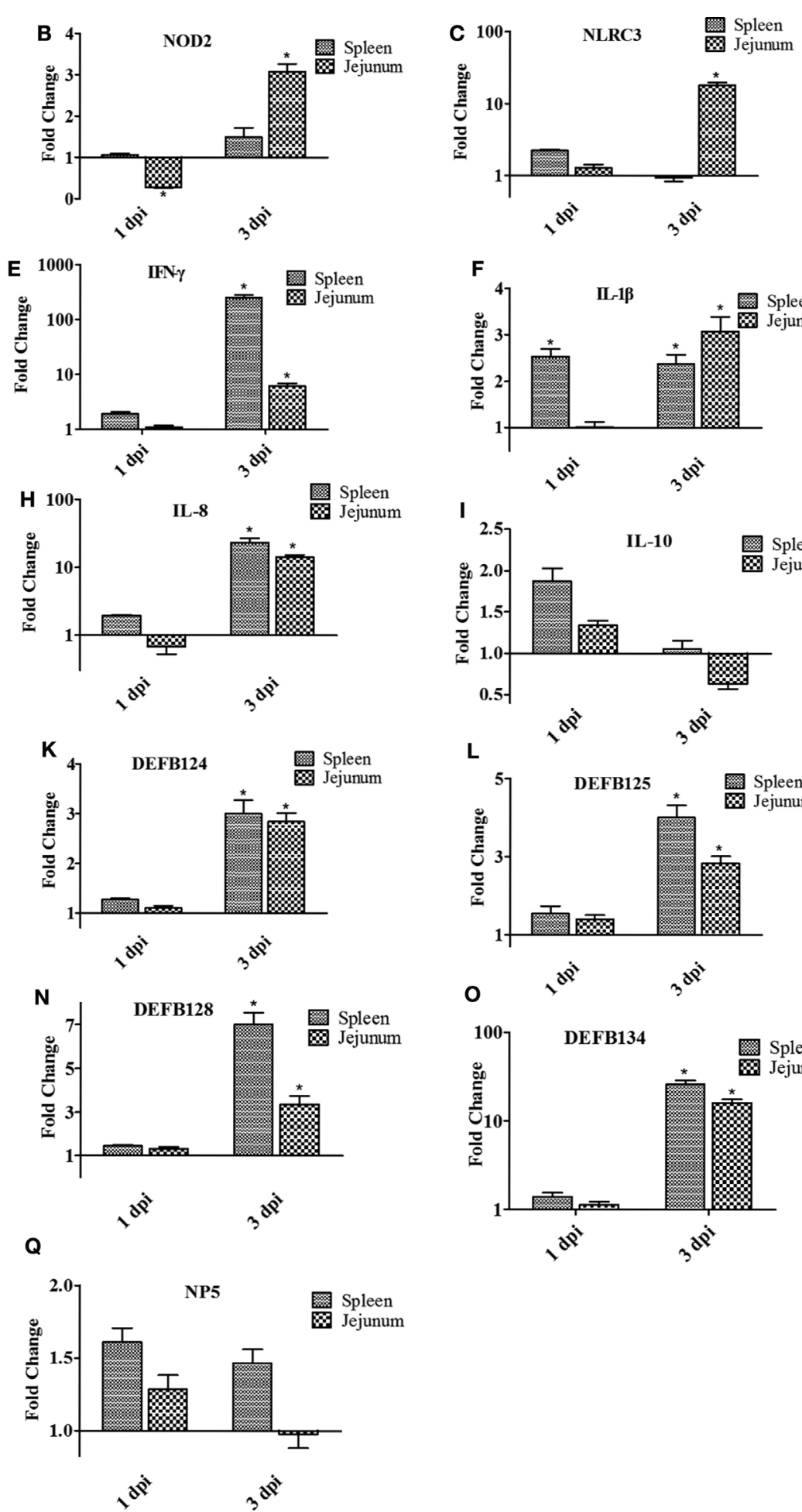
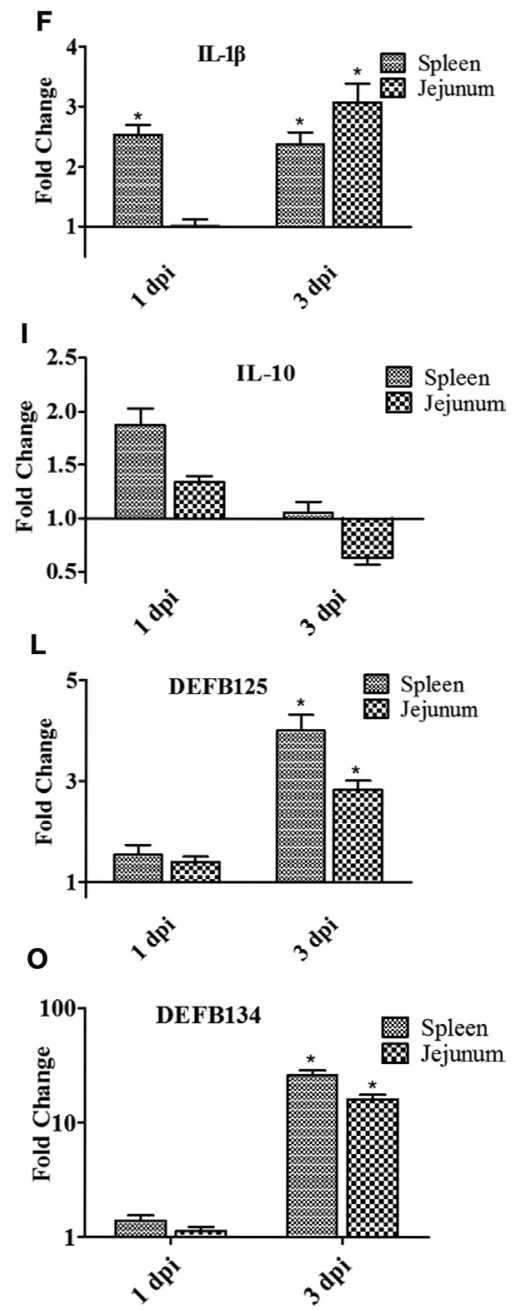

FIGURE 8 | The expression of immune-related genes in the spleen and jejunum of rabbits at 1 and 3 dpi. (A) NOD1, (B) NOD2, (C) NLRC3, (D) NLRX1, (E) IFN- $\gamma, \mathbf{( F ) ~ I L - 1 \beta , ~ ( G ) ~ I L - 4 , ~ ( H ) ~ I L - 8 , ~ ( I ) ~ I L - 1 0 , ~ ( J ) ~ D E F B 1 1 4 , ~ ( K ) ~ D E F B 1 2 4 , ~ ( L ) ~ D E F B 1 2 5 , ~ ( M ) ~ D E F B 1 2 7 , ~ ( N ) ~ D E F B 1 2 8 , ~ ( O ) ~ D E F B 1 3 4 , ~ ( P ) ~ D E F B 1 3 5 , ~ a n d ~ ( Q ) ~ N P 5 . ~}$ The fold change represents gene expression in diet including Bacillus subtilis compared to that of controls. Bars represented the means \pm SDs of three independent experiments (five rabbits per experiment). Mann-Whitney $U$ test was conducted to examine differences. ${ }^{\star} P<0.05$. 
about NLRs in rabbits, and only the predicted sequences are available in Genebank. At present, the full lengths of some NLRs in rabbits have been obtained, and their biological functions (no published data) have been verified. In this study, the dietary administration of B. subtilis increased the NOD1, NLRC3, and NLRX1. NLRs detect and sense microbial components and then lead to the activation of an inflammatory response and promote the secretion of cytokines $(34,35)$. A previous study has shown that NLRCs induce IFN- $\gamma$ and IL- $1 \beta$ gene expression in Japanese flounder (36). Olive flounder NOD1 not only plays a major role in inhibition of Edwardsiella tarda growth but also enhances the activation of IL-1 $\beta$, which is in turn implicated in the initiation of inflammation and host defense (37). IL-1 $\beta$ is a major proinflammatory cytokine that induces its own expression as well as the expression of other proinflammatory cytokines, adhesion molecules, and chemokines such as IL- 6 , IL- 8 , and TNF- $\alpha$, in turn initiating an inflammatory response and recruitment of antimicrobial cells such as neutrophils and macrophages (38). The main biological activity of IFN- $\gamma$ is immune regulation, which includes innate and adaptive immunity. In previous studies, pretreatment with B. subtilis, the IFN- $\gamma$ transcript levels remained high after infection with Citrobacter rodentium (39, $40)$. It has been shown to be a proinflammatory factor and has an antiviral effect (41). In this study, IFN- $\gamma$, IL- $1 \beta$, and IL- 8 were upregulated by dietary $B$. subtilis. It may be due to the activation of NLRs.

Previous studies have suggested that several probiotics induce innate immunity through $\beta$-defensin 2 induction in Caco- 2 cells (42). The antimicrobial peptide (AMP) is a class of molecules that occurs in all forms of life, from multicellular organisms to bacterial cells. In higher organisms, AMPs contribute to innate immunity and are part of the first line of defense against various microorganisms, including Gram-positive and Gram-negative bacteria, fungi, and viruses (43). The defensins are small, cationic, cystine-rich AMPs with broad antimicrobial activities. They can recruit immature dendritic cells and macrophages to reach the skin and mucosal tissues of microbial invasion through chemokine receptors, thus inducing specific immunity of pathogenic bacteria. In mammals, defensins are divided into $\alpha-, \beta$-, and $\theta$-defensins (44). The results of the present study suggest that the $\alpha$-defensin and $\beta$-defensin were induced by a diet with $B$. subtilis. On the one hand, defensins can directly act on pathogenic microorganisms and more importantly participate in the innate immunity as well as the initiation and regulation of adaptive immune response. Previous study has demonstrated that lactobacilli and the VSL\#3 bacterial mixture restored intestinal barrier function through the upregulation of human-beta defensin $2 \mathrm{via}$ induction of proinflammatory pathways of the nuclear factor- $\mathrm{\kappa B}$ (45). However, the genomic structure and PGN of bacteria also exist in the killed cells. They can be identified by the host PRRs, which trigger the innate immune response. So killed cells are able to induce a certain degree of protective immune responses. Our results indicated that live Bacillus showed stronger ability in induce innate immunity than the killed cells when used the same dose in the RK-13 cells. To the best of our knowledge, this research is the first report on the innate immune response to $B$. subtilis in rabbits.
In return, the survival rate of rabbits fed $B$. subtilis was higher than that of the controls after they were challenged with E. coli. This conclusion was supported by increased body weights, serum immunoglobulin, and immune organ index and enhanced expression of major innate immunity genes involved in initiating and regulating immune response against $E$. coli. It is worth noting that $\beta$-defensin was significantly upregulated in the $B$. subtilis feeding group postinfection with $E$. coli, especially DEFB 114, DEFB 134, and DEFB 135. Given that $\beta$-defensin has a strong antibacterial ability, the higher expression of $\beta$-defensin may be the most important reason for disease resistance. Meanwhile, the present results showed that the number of $E$. coli in the cecal contents significantly declined with a diet of $B$. subtilis during the test days. As various reports have shown, several bacilli have established antimicrobial properties against various Gram-positive and Gram-negative pathogenic bacteria (46). In this study, BYS2, BQ3, and BD17 have also shown strong inhibition against $E$. coli in vitro and therefore possess potent immunostimulatory capacities. It is also important that the intestinal flora is mainly composed of anaerobic bacteria, and relatively few aerobic bacteria. $B$. subtilis can inhibit the growth of pathogenic $E$. coli by consuming oxygen in the intestine and regulating the balance of intestinal flora. Previous research showed that B. subtilis PY79 ${ }^{\mathrm{hr}}$ can inhibit colonization and persistence of Salmonella enteritidis, C. perfringens, and E. coli (47). In the intestine, B. subtilis may prevent the overgrowth of E. coli, enhance the resistance to $E$. coli invasion of the intestinal tract, and ameliorate disease processes. As a result, a diet including $B$. subtilis decreased the concentration of E. coli in vivo. B. subtilis may be competitive exclusion approaches in the control of infection with enteric pathogens.

In conclusion, the five $B$. subtilis that were selected for in vitro experiment showed good probiotic potential in rabbits. Enhancing the disease resistance of rabbits fed with $B$. subtilis may due to the probiotic's influence on the improved growth performance, serum immunoglobulin, immune organ index, intestinal homeostasis, and immune response of rabbits, as well as its antibacterial benefits. The data from this study enhance the understanding of the mechanism of action between probiotics and the host, allowing for the development of probiotic-based strategies to prevent pathogenic infection.

\section{AUTHOR CONTRIBUTIONS}

MG and FW designed and conducted the study, performed most of the experiments, and wrote the manuscript. GH and RL performed the calculation with support from QQ. FW and NL collected samples. TC and LW discussed the results and revised the manuscript.

\section{ACKNOWLEDGMENTS}

This study was sponsored by the key research project of Shandong Province "Research of a new probiotics for anti-infection, environmental improvement and alternative antibiotic and their products development" (2016GNC110014). 


\section{REFERENCES}

1. Simoneit C, Burow E, Tenhagen BA, Käsbohrer A. Oral administration of antimicrobials increase antimicrobial resistance in E. coli from chicken - a systematic review. Prev Vet Med (2014) 118:1-7. doi:10.1016/j.prevetmed.2014.11.010

2. Sullivan A, Edlund C, Nord CE. Effect of antimicrobial agents on the ecological balance of human microflora. Lancet Infect Dis (2001) 1:101-14. doi:10.1016/ S1473-3099(01)00066-4

3. Lupindu AM, Dalsgaard A, Msoffe PLM, Ngowi HA, Mtambo MM, Olsen JE. Transmission of antibiotic-resistant Escherichia coli between cattle, humans and the environment in peri-urban livestock keeping communities in Morogoro, Tanzania. Prev Vet Med (2015) 118:477-82. doi:10.1016/j. prevetmed.2014.12.005

4. Cutting SM. Bacillus probiotics. Food Microbiol (2011) 28:214-20. doi:10.1016/j.fm.2010.03.007

5. Sanders ME, Morelli L, Tompkins TA. Sporeformers as human probiotics: Bacillus, Sporolactobacillus, and Brevibacillus. Compr Rev Food Sci Food Saf (2003) 2:101-10. doi:10.1111/j.1541-4337.2003.tb00017.x

6. Zhou M, Wang H, Ze-Yang LI. Study on resistance to stress factors of Bacillus subtilis from swine intestinal juice. JAnhui Agricultural Univer (2013) 40:519-22. doi:10.13610/j.cnki.1672-352x.2013.04.028

7. Jung WJ, Mabood F, Souleimanov A, Whyte LG, Niederberger TD, Smith DL. Antibacterial activity of antagonistic bacterium Bacillus subtilis DJM-51 against phytopathogenic Clavibacter michiganense subsp. michiganense ATCC 7429 in vitro. Microb Pathog (2014) 77:13-6. doi:10.1016/j.micpath.2014.10.008

8. Teuber M, Meile L, Schwarz F. Acquired antibiotic resistance in lactic acid bacteria from food. Antonie Van Leeuwenhoek (1999) 76:115-37. doi:10.102 3/A:1002035622988

9. Vizoso Pinto MG, Franz CM, Schillinger U, Holzapfel WH. Lactobacillus spp. with in vitro probiotic properties from human faeces and traditional fermented products. Int J Food Microbiol (2006) 109:205-14. doi:10.1016/j. ijfoodmicro.2006.01.029

10. Pagnini C, Saeed R, Bamias G, Arseneau KO, Pizarro TT, Cominelli F. Probiotics promote gut health through stimulation of epithelial innate immunity. Proc Natl Acad Sci U S A (2010) 107:454-9. doi:10.1073/pnas.0910307107

11. Kady MFE, Hassan ER, Radwan EH, Rabie NS, Rady MM. Effect of probiotic on necrotic enteritis in chickens with the presence of immunosuppressive factors. Global Vet (2012) 9:345-51. doi:10.5829/idosi.gv.2012.9.3.63228

12. Levkut $M$, Revajová V, Lauková $A$, Ševčíková Z, Spišáková V, Faixová $Z$, et al. Leukocytic responses and intestinal mucin dynamics of broilers protected with Enterococcus faecium EF55 and challenged with Salmonella enteritidis. Res Vet Sci (2012) 93:195-201. doi:10.1016/j.rvsc.2011.06.021

13. Springer S, Selbitz HJ. The control of necrotic enteritis in sucking piglets by means of a Clostridium perfringens toxoid vaccine. Fems Immunol Med Microbiol (1999) 24:333-6. doi:10.1111/j.1574-695X.1999.tb01302.x

14. Swennes AG, Buckley EM, Madden CM, Byrd CP, Donocoff RS, Rodriguez L, et al. Enteropathogenic Escherichia coli prevalence in laboratory rabbits. Vet Microbiol (2013) 163:395-8. doi:10.1016/j.vetmic.2013.01.006

15. Larcombe S, Hutton ML, Lyras D. Involvement of bacteria other than Clostridium difficile in antibiotic-associated diarrhoea. Trends Microbiol (2016) 24:463-76. doi:10.1016/j.tim.2016.02.001

16. Mccracken VJ, Gaskins HR, Tannock GW. Probiotics and the immune systems. In: Tannock GW, editor. Probiotics: A Critical Review. Wymondham, UK: Horizon Scientific Press (1999). p. 85-112.

17. Verschuere L, Rombaut G, Sorgeloos P, Verstraete W. Probiotic bacteria as biological control agents in aquaculture. Microbiol Mol Biol Rev (2000) 64:655-71. doi:10.1128/MMBR.64.4.655-671.2000

18. Lee SH, Ingale SL, Kim JS, Kim KH, Lokhande A, Kim EK, et al. Effects of dietary supplementation with Bacillus subtilis LS 1-2 fermentation biomass on growth performance, nutrient digestibility, cecal microbiota and intestinal morphology of weanling pig. Anim Feed Sci Technol (2014) 188:102-10. doi:10.1016/j.anifeedsci.2013.12.001

19. Al-Fataftah AR, Abdelqader A. Effects of dietary Bacillus subtilis on heat-stressed broilers performance, intestinal morphology and microflora composition. Anim Feed Sci Technol (2014) 198:279-85. doi:10.1016/j. anifeedsci.2014.10.012

20. Fonseca AP, Falcão L, Kocher A, Spring P. Effects of dietary mannan oligosaccharide in comparison to oxytetracycline on performance of growing rabbits. Proceedings of the 8th World Rabbit Congress, September 7-10, 2004. Pueblo, Mexico (2004).
21. Pinheiro V, Guedes CM, Outor-Monteiro D, Mourão JL. Effects of fibre level and dietary mannanoligosaccharides on digestibility, caecal volatile fatty acids and performances of growing rabbits. Anim Feed Sci Technol (2009) 148:288-300. doi:10.1016/j.anifeedsci.2008.03.010

22. SB/T 10317-1999. Measurement of Proteinase Activity [S]. Beijing: Standards Press of China (1999).

23. Zhang D, Rui L, Li J. Lactobacillus reuteri ATCC 55730 and L22 display probiotic potential in vitro and protect against Salmonella-induced pullorum disease in a chick model of infection. Res Vet Sci (2012) 93:366-73. doi:10.1016/j. rvsc.2011.06.020

24. Patel AK, Ahire JJ, Pawar SP, Chaudhari BL, Chincholkar SB. Comparative accounts of probiotic characteristics of Bacillus spp. isolated from food wastes. Food Res Intern (2009) 42:505-10. doi:10.1016/j. foodres.2009.01.013

25. Luo Y, Ma B-C, Zou L-K, Cheng J-G, Cai Y-H, Kang J-P, et al. Identification and characterization of lactic acid bacteria from forest musk deer feces. Afr J Microbiol Res (2012) 6:5871-81. doi:10.5897/AJMR12.807

26. Sen S, Ingale SL, Kim YW, Kim JS, Kim KH, Lohakare JD, et al. Effect of supplementation of Bacillus subtilis LS 1-2 to broiler diets on growth performance, nutrient retention, caecal microbiology and small intestinal morphology. Res Vet Sci (2012) 93:264-8. doi:10.1016/j.rvsc.2011.05.021

27. Thirabunyanon M, Thongwittaya N. Protection activity of a novel probiotic strain of Bacillus subtilis against Salmonella enteritidis infection. Res Vet Sci (2012) 93:74-81. doi:10.1016/j.rvsc.2011.08.008

28. Bandyopadhyay P, Das Mohapatra PK. Effect of a probiotic bacterium Bacillus circulans PB7 in the formulated diets: on growth, nutritional quality and immunity of Catla catla (Ham.). Fish Physiol Biochem (2009) 35:467-78. doi:10.1007/s10695-008-9272-8

29. Thanh LP, Jamikorn U. Effects of probiotic supplement (Bacillus subtilis and Lactobacillus acidophilus) on feed efficiency, growth performance, and microbial population of weaning rabbits. Asian-australas J Anim Sci (2017) 30(2):198. doi:10.5713/ajas.15.0823

30. Turner JL, Dritz SS, Higgins JJ, Minton JE. Effects of Ascophyllum nodosum extract on growth performance and immune function of young pigs challenged with Salmonella typhimurium. JAnim Sci (2002) 80:1947-53. doi: $10.2527 / 2002.8071947 x$

31. Li SP, Zhao XJ, Wang JY. Synergy of Astragalus polysaccharides and probiotics (Lactobacillus and Bacillus cereus) on immunity and intestinal microbiota in chicks. Poult Sci (2009) 88:519-25. doi:10.3382/ps.2008-00365

32. Richards JD, Gong J, de Lange CFM. The gastrointestinal microbiota and its role in monogastric nutrition and health with an emphasis on pigs: current understanding, possible modulations, and new technologies for ecological studies. Can Vet J (2005) 85(4):421-35. doi:10.4141/A05-049

33. Tannock GW. Molecular methods for exploring the intestinal ecosystem. $\mathrm{Br}$ J Nutr (2002) 87(S2):S199-201. doi:10.1079/BJNBJN/2002538

34. Brodsky IE, Monack D. NLR-mediated control of inflammasome assembly in the host response against bacterial pathogens. Semin Immunol (2009) 21:199-207. doi:10.1016/j.smim.2009.05.007

35. Williams A, Flavell RA, Eisenbarth SC. The role of NOD-like receptors in shaping adaptive immunity. Curr Opin Immunol (2010) 22:34-40. doi:10.1016/j. coi.2010.01.004

36. Unajak S, Santos MD, Hikima J, Jung TS, Kondo H, Hirono I, et al. Molecular characterization, expression and functional analysis of a nuclear oligomerization domain proteins subfamily c (NLRC) in Japanese flounder (Paralichthys olivaceus). Fish Shellfish Immunol (2011) 31(2):202-11. doi:10.1016/j. fsi.2011.05.007

37. Smith DE, Renshaw BR, Ketchem RR, Kubin M, Garka KE, Sims JE. Four new members expand the interleukin-1 superfamily. JBiol Chem (2000) 275(2):1169-75. doi:10.1074/jbc.275.2.1169

38. Wang YG, Fang WL, Wei J, Wang T, Wang N, Ma JL, et al. The involvement of nlrx1 and nlrp3 in the development of nonalcoholic steatohepatitis in mice. J Chin Med Assoc (2013) 76(12):686-92. doi:10.1016/j.jcma.2013.08.010

39. Johnsonhenry KC, Nadjafi M, Avitzur Y, Mitchell DJ, Ngan BY, Galindomata $\mathrm{E}$, et al. Amelioration of the effects of Citrobacter rodentium infection in mice by pretreatment with probiotics. J Infect Dis (2005) 191(12):2106. doi: $10.1086 / 430318$

40. D’Arienzo R, Maurano F, Mazzarella G, Luongo D, Stefanile R, Ricca E, et al. Bacillus subtilis spores reduce susceptibility to Citrobacter rodentium-mediated enteropathy in a mouse model. Res Microbiol (2006) 157(9):891-7. doi:10.1016/j.resmic.2006.06.001 
41. Pestka S, Krause CD, Walter MR. Interferons, interferon-like cytokines, and their receptors. Immunol Rev (2004) 202(1):8-32. doi:10.1111/j.0105-2896. 2004.00204.x

42. Wehkamp J, Harder J, Kai W, Meissner BW, Schlee M, Enders C, et al. NF-kappaB- and AP-1-mediated induction of human beta defensin-2 in intestinal epithelial cells by Escherichia coli Nissle 1917: a novel effect of a probiotic bacterium. Infecti Immun (2004) 72:5750-8. doi:10.1128/ IAI.72.10.5750-5758.2004

43. Tavares LS, Silva CS, De Souza VC, Da SV, Diniz CG, Santos MO. Strategies and molecular tools to fight antimicrobial resistance: resistome, transcriptome, and antimicrobial peptides. Front Microbiol (2013) 4:412. doi:10.3389/ fmicb.2013.00412

44. Wang W, Cole AM, Hong T, Waring AJ, Lehrer RI. Retrocyclin, an antiretroviral theta-defensin, is a lectin. J Immunol (2003) 170:4708-16. doi:10.4049/ jimmunol.170.9.4708

45. Schlee M, Harder J, Köten B, Stange EF, Wehkamp J, Fellermann K. Probiotic lactobacilli and VSL\#3 induce enterocyte beta-defensin 2. Clin Exp Immunol (2008) 151:528-35. doi:10.1111/j.1365-2249.2007.03587.x
46. Yilmaz M, Soran H, Beyatli Y. Antimicrobial activities of some Bacillus spp. strains isolated from the soil. Microbiol Res (2006) 161:127-31. doi:10.1016/j. micres.2005.07.001

47. Ragione RML, Woodward MJ. Competitive exclusion by Bacillus subtilis, spores of Salmonella enterica, serotype enteritidis and Clostridium perfringens, in young chickens. Vet Microbiol (2003) 94(3):245. doi:10.1016/ S0378-1135(03)00077-4

Conflict of Interest Statement: The authors declare that the research was conducted in the absence of any commercial or financial relationships that could be construed as a potential conflict of interest.

Copyright (C) $2017 \mathrm{Guo}, \mathrm{Wu}, \mathrm{Hao}, \mathrm{Qi}, \mathrm{Li}, \mathrm{Li}$, Wei and Chai. This is an open-access article distributed under the terms of the Creative Commons Attribution License (CC $B Y)$. The use, distribution or reproduction in other forums is permitted, provided the original author(s) or licensor are credited and that the original publication in this journal is cited, in accordance with accepted academic practice. No use, distribution or reproduction is permitted which does not comply with these terms. 